\title{
Invasive Aspergillosis Associated Bacterial Infection in the Nasal Septum After Sphenoid Sinus Surgery
}

\author{
Hyun Gi Sohn', Min Ho Yoon ${ }^{1}$, Tae Eun Kim², and Nam-Kyung Yeo ${ }^{1}$ \\ ${ }^{1}$ Departments of Otolaryngology, ${ }^{2}$ Pathology, Gangneung Asan Hospital, University of Ulsan College of Medicine, Gangneung, Korea
}

접형동 수술 후 비중격에 발생한 침습성 아스페르길루스증

손현기 $^{1} \cdot$ 윤민호 $^{1} \cdot$ 김태은 $^{2} \cdot$ 여남경 ${ }^{1}$

울산대학교 의과대학 강릉아산병원 이비인후과학교실, ${ }^{1}$ 병리학교실 ${ }^{2}$

\author{
Received December 27, 2016 \\ Revised March 19,2017 \\ Accepted March 27, 2017 \\ Address for correspondence \\ Nam-Kyung Yeo, MD, PhD \\ Department of Otolaryngology, \\ Gangneung Asan Hospital, \\ University of Ulsan \\ College of Medicine, \\ 38 Bangdong-gil, Sacheon-myeon, \\ Gangneung 25440, Korea \\ Tel $+82-33-610-3308$ \\ Fax $+82-33-610-4960$ \\ E-mailnewnew1@hanmail.net
}

Nasal septal infection can result from progression of a fungal infection from the adjacent sinuses. Nasal septal fungal abscesses complicating nasal trauma, surgical procedures, sinus, and dental infections have previously been reported in a small number of cases. Adequate management involves early diagnosis, prompt empiric antifungal therapy, and surgical debridement in order to prevent the development of life-threatening complications. We report a rare case of nasal septum necrosis from Aspergillus infection in a 79-year-old man with diabetes mellitus and chronic renal failure following endoscopic sphenoid sinus surgery due to an isolated sphenoid fungal ball.

Korean J Otorhinolaryngol-Head Neck Surg 2018;61(10):541-5

Key Words Aspergillosis $\cdot$ Septal abscess $\cdot$ Sphenoid fungal ball.

\section{Introduction}

Fungal balls are more common in patients with intact immune systems and are most commonly seen in the maxillary sinuses. They may be also seen at other sites, including isolated to the sphenoid sinus. ${ }^{1)}$ In contrast, invasive fungal infections of the paranasal sinuses usually occur in an immunocompromised host. These can be destructive and fatal entities that require emergent surgical intervention. ${ }^{2)}$ Nasal septal fungal abscesses complicating nasal trauma, surgical procedures, sinus, and dental infections have previously been reported in a small number of cases. ${ }^{2-4)}$ We report a rare case of nasal septum necrosis by Aspergillus infection in a 79-year-old man with diabetes mellitus (DM) and chronic renal failure (CRF).

This is an Open Access article distributed under the terms of the Creative Commons Attribution Non-Commercial License (https://creativecommons.org/licenses/by-nc/4.0) which permits unrestricted non-commercial use, distribution, and reproduction in any medium, provided the original work is properly cited.
This occurred after endoscopic sphenoid sinus surgery, and was due to an isolated sphenoid fungal ball. He was successfully treated with surgical drainage and postoperative antifungal therapy.

\section{Case}

A 79-year-old man with a history of DM and CRF visited our hospital with a chief complaint of headache for several months duration. His DM had not been well controlled on oral hypoglycemic agents (glimepiride $2 \mathrm{mg} /$ metformin 500 $\mathrm{mg}$ ) and long-acting recombinant human insulin treatment (lantussolostar $30 \mathrm{U}$ ). He had no specific therapy for CRF. Blood sugar level was $239 \mathrm{mg} / \mathrm{dL}$, and HbAlc was 9.4\%. Blood creatinine level was $2.0 \mathrm{mg} / \mathrm{dL}$. During initial nasal physical examination, there were no specific nasal mucosa findings seen on nasal endoscopy. However, computed tomography 
Fig. 1. Computed tomography scans of preoperative state. Computed tomography imaging showed total opacification with intralesional calcification (arrow) in the left sinus.
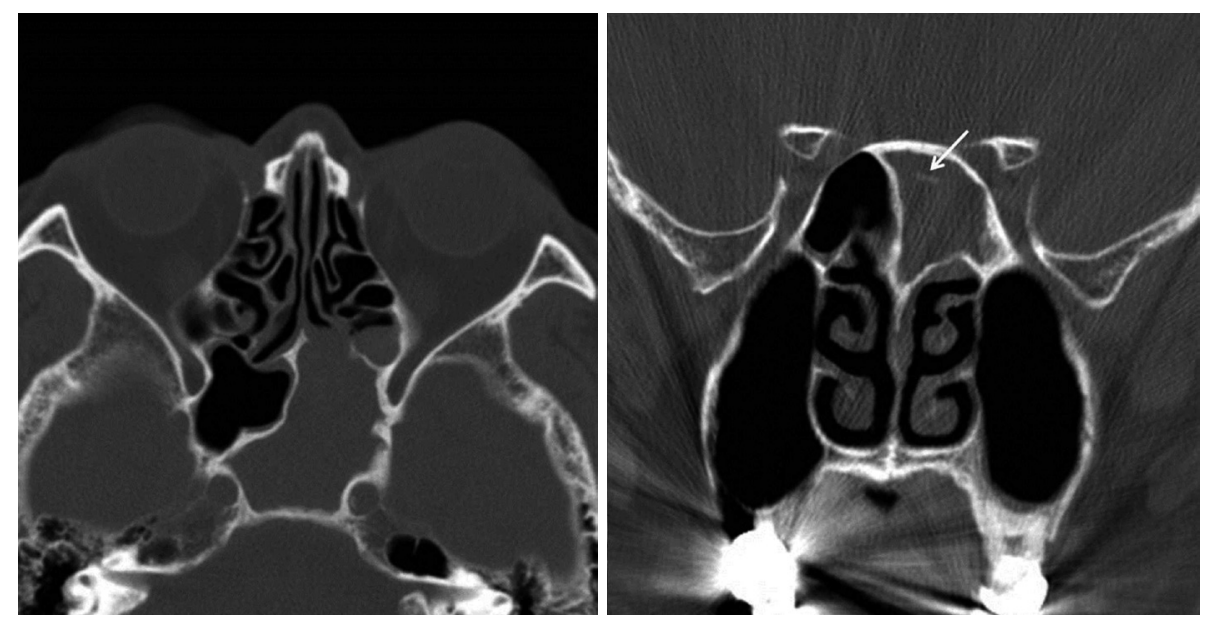

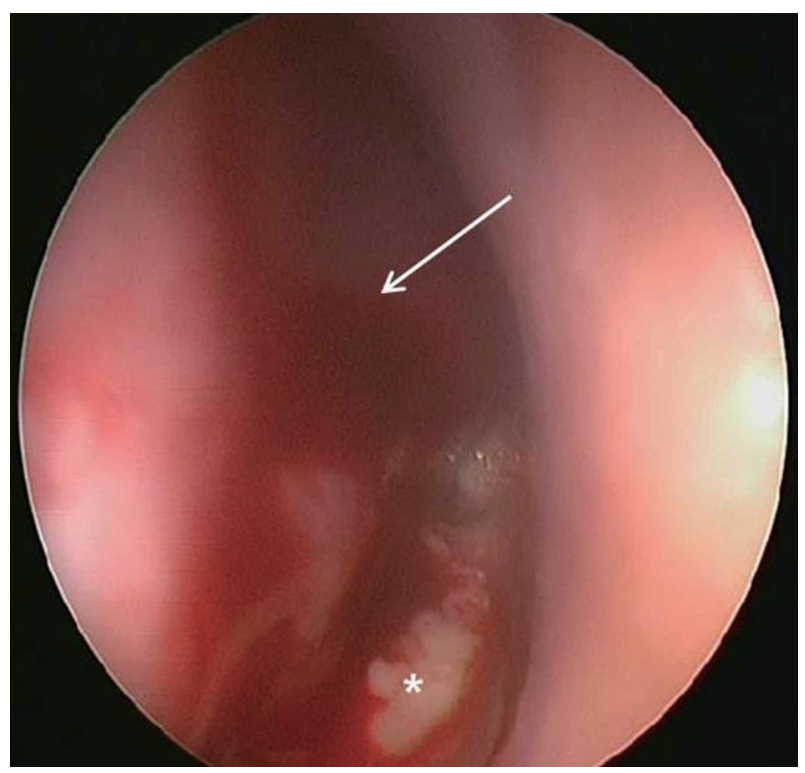

Fig. 2. Endoscopic photographs of the first visit after left sphenoidotomy. On examination, swelling of the left nasal septum (arrow) was found. When the septal mucosa was incised, a large volume of frank pus (star) was drained.

(CT) imaging showed total opacification with intralesional calcification in the left sinus (Fig. 1). CT scans revealed obstruction of the sphenoethmoidal recess and thickening of the left sphenoid sinus wall. Endonasal endoscopic sphenoidotomy was performed under general anesthesia, and the patient was found to have fungus balls in his left sphenoid sinus, all of which were removed. The patient was discharged with a course of antibiotics (levofloxacin $500 \mathrm{mg}$ once a day for 1 week). The pathologic finding of the fungal balls was degenerated fungal hyphae, consistent with aspergillosis. There was no invasiveness of fungal hyphaeinto mucosa and bone.

Two weeks post-surgery, the patient developed nasal pain and increasing nasal congestion. On examination, he was found to have swelling of his left nasal septum, consistent with an abscess. When the septal mucosa was incised, a large volume of frank pus was drained, with cultures sent for analysis (Fig. 2). Antibiotics were resumed, and the abscess cavity was incised and drained twice daily. Cultures from the initial drainage were positive for methicillin-resistant coagulase-negative Staphylococcus. As a result the patient was treated with intravenous vancomycin. After two weeks with vancomycin and dressing treatment, his symptoms improved. However minimal caudal septum swelling was observed, with CT imaging showing a small persistent septal abscess (Fig. 3). The patient was taken to the operating room for wide debridement under local anesthesia. Purulent discharge and some granulations were drained. Culture was repeated and a biopsy was performed. The results indicated infection with methicillinresistant coagulase-negative Staphylococcus and active inflammation. Following surgery, the patient complained of residual nasal pain, and there remained some caudal septal swelling. One week later, wide debridement and tissue biopsy under general anesthesia was performed, revealing purulent fluid and loss of the anterior septal cartilage. All suspicious inflammatory lesions, including septal bone, were removed. Cultures showed no bacterial growth, however biopsy revealed acute and chronic inflammation with Gomorimethenamine silver and Periodic acid-Schiff positive fungal hyphae. The patient was diagnosed as having aspergillosis with bony septal destruction (Fig. 4). After consultation with the infectious disease team, the patient was started on a course of voriconazole.

His condition improved after two weeks of treatment with intravenous voriconazole. He was discharged in a stable condition and without evidence of abscess reaccumulation. The 
patient was prescribed oral voriconazole for a further 6 months. On follow-up, the patient was free of fungal infection and doing well without any adverse symptoms. Although endoscopy revealed several septal perforations due to wide surgical debridement, no evidence of infection was seen on the mucosae of the septum or sphenoid sinus (Fig. 5). He has been followed up for 12 months without recurrence.

\section{Discussion}

Nasal septal abscess is defined as a collection of purulent material between the cartilaginous or bony septum and the mucoperichondrium or mucoperiosteum. ${ }^{3)}$ Although they usually occur secondary to injury, they can present without antecedent trauma, and as a result of atypical organisms such as fungi. ${ }^{2)}$ Fungal nasal septal abscess is not frequently encountered and has rarely been documented, with only a small number of foreign case reports or experiences published. ${ }^{2-5)}$ There are two previous reported cases in Korea. ${ }^{6,7)}$

Most previous fungal nasal septal abscess cases in immunocompromised patients spontaneously occurred. ${ }^{3-7)}$ One case happened in an immunocompetent patient who had under-
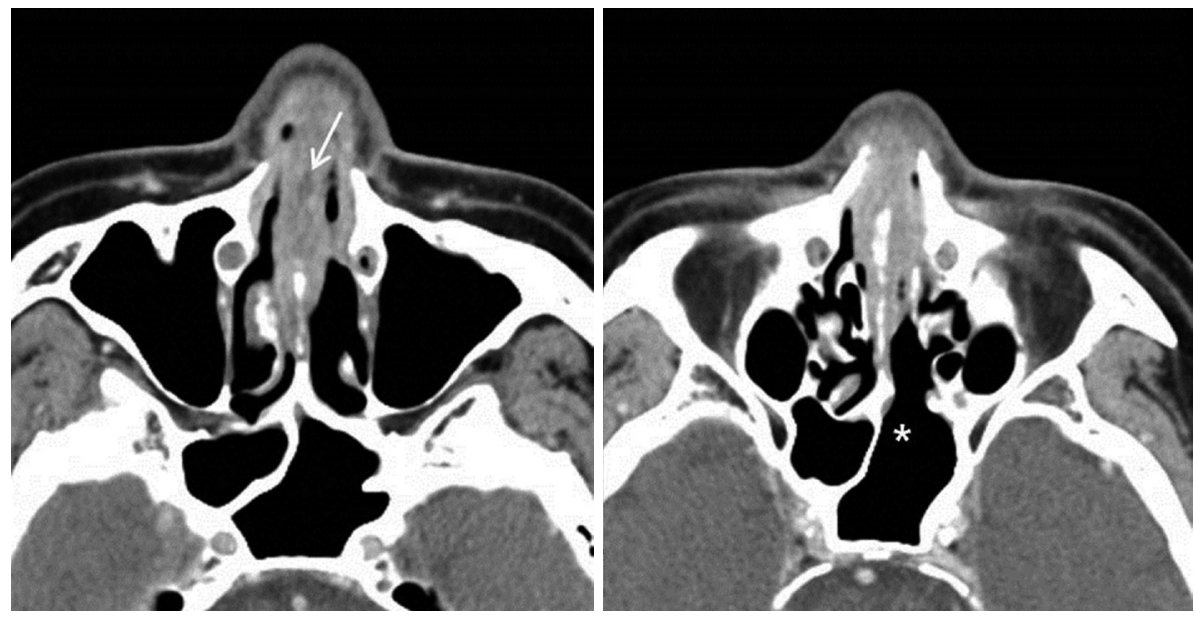

Fig. 3. Computed tomography scans after incision and drainage. Computed tomography imaging showed small persistent septal abscess (arrow). Left sphenoid (star) had completely healed after endoscopic surgery.
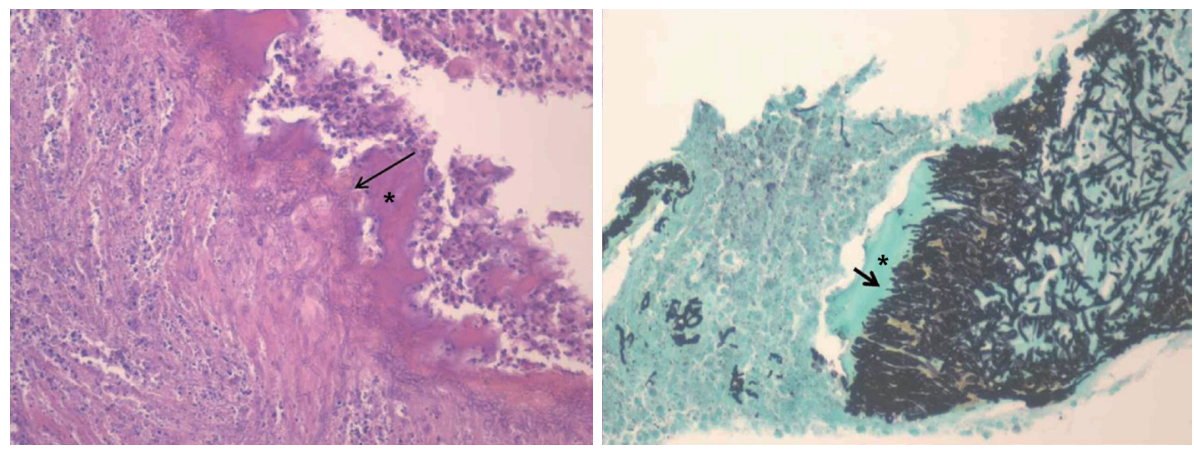

Fig. 4. Microscopic findings. Biopsy revealed acute and chronic inflammation with Gomori methenamine silver (GMS) and Periodic acid-Schiff positive fungal hyphae. Aspergillosis (arrows) invaded directly into septal bone (stars) on hematoxylin and eosin stain $(\times 40)$ and GMS stain $(\times 200)$ was seen.
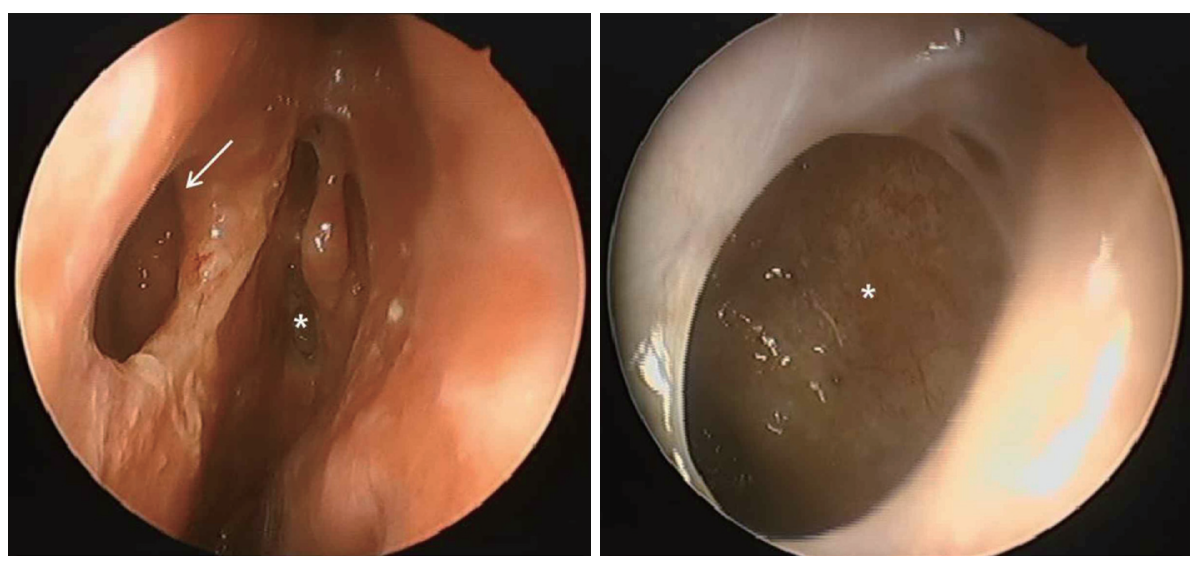

Fig. 5. Endoscopic photograph showing the nasal cavity after 6 months of treatment. Several septal perforations (arrow) were seen due to wide debridement, however there was no evidence of infection at the mucosa's of the septum and sphenoid sinus (stars). 
gone endoscopic sinus surgery due to maxillary sinus fungal ball while using postoperative steroid. ${ }^{2)}$ Interestingly, our caseof an immunocompromised patient was caused by sphenoid sinus surgery due to sphenoid sinus fungal ball. There have been no reports of septal abscess after sphenoid sinus surgery. On the other hands, there were nasal septal abscesses complicated by acute spheno-ethmoiditis or isolated sphenoiditis. ${ }^{89}$ Sphenoid sinus and nasal septum are posteriorly connected with mucosa and bony structure. Therefore, each infection in sphenoid sinus and nasal septum can be spread to each other. In this case, species of fungal ball in sphenoid sinus was Aspergillus and species of fungus in septal bone was also Aspergillus. The patient's previous sphenoid sinus surgery may have created traumatic entry points at her nasal septum for Aspergillus infection. Especially, the combination of surgical trauma and uncontrolled DM may have set the stage for an invasive infection.

Patients with nasal septal fungal infection usually present with nasal obstruction and pain. Additional symptoms can include rhinorrhea, fever, and bleeding. Few symptomatic differences exist between septal fungal infection and bacterial infection. However, direct clinical inspection may reveal a swelling with purple-black crusting necrotic tissue at the site of fungal infection. ${ }^{2)}$ Typical endoscopic examination may show a purple-black crusting, necrosis, pale mucosal areas, and, sometimes, recognition of hyphae. ${ }^{10)}$ In addition, atypical infection should be suspected if the patient does not respond to standard treatment measures. ${ }^{5)}$ If a patient is immunocompromised, invasive fungal infection including polymicrobial infection should be considered as part of the differential diagnosis. ${ }^{2-5)}$ Hematologic malignancies, aplastic anemia, long-term steroid use, acquired immunodeficiency syndrome, uncontrolled DM, and diseases of iron metabolism and immunosuppressive therapy for organ transplantation are the most commonly encountered underlying conditions. ${ }^{10)}$ In our case, although there was no necrosis of the septal mucosa, the patient was immunocompromised due to DM and CRF, and didn't respond adequately to broad spectrum antibiotics and daily dressing treatment.

Early diagnosis and treatment are essential to prevent the associated complications. These range from cosmetic disfiguration such as saddle deformity of the nasal bridge, to life threatening invasive fungal infections such as brain abscess, fungal sinusitis, and cavernous sinus thrombosis. ${ }^{2)}$ Furthermore, immunocompromised patients are significantly more likely to develop intracranial complications from their infec- tions compared to those with intact defense mechanisms. These rhinologic infections can rapidly progress to irreversible neurologic deficits or even patient death if they are not promptly and aggressively managed. Hematogenous spread of bacteria or fungal elements present in nasal septal abscesses occurs through superficial, glandular or periosteal venous networks. ${ }^{11)}$ Definitive diagnosis of nasal septal aspergillosis often requires histopathologic examination and fungal staining with culture of the debrided nasal tissue to show invasive septate hyphae. Accurate identification of the fungal organism is key to guiding treatment. In our case, first biopsy could not find the fungus, because the biopsy was performed under the local anesthesia and the amount of obtained tissue was too small. Second biopsy was done under the general anesthesia, and we obtained much tissue including septal bone to detect the invasiveness of fungus. Therefore, it is important to get large specimens for early and exact diagnosis of invasive fungal infection.

When nasal septal fungal infection is suspected, treatment includes the control of underlying predisposing conditions, surgical debridement and antifungal agents. The latter must be promptly initiated because of the potentially life-threatening consequences of delayed therapy. ${ }^{4,10)}$ Voriconazole is the primary drug for the treatment of invasive aspergillosis. ${ }^{12)}$ The optimal duration of therapy is unknown. However, extrapolating from the Infectious Diseases Society of America treatment guidelines for pulmonary Aspergillus infection, a duration of at least 6 to 12 weeks of therapy is reasonable. ${ }^{12)}$ After the patient improves, he or she should be followed up long term to ensure a successful and long-lasting response to treatment. Although rare, fungal infection in immunocompetent hosts can occur and requires a certain degree of suspicion and accurate identification for complete treatment response. Therefore, therapy can be extended beyond this period depending on the clinical response and immune status of the patient. As there was a definite bony invasion by aspergillosis, our patient received almost 6 months of therapy to avoid recurrence.

\section{REFERENCES}

1) Karkas A, Rtail R, Reyt E, Timi N, Righini CA. Sphenoid sinus fungus ball. Eur Arch Otorhinolaryngol 2013;270(3):893-8.

2) Walker R, Gardner L, Sindwani R. Fungal nasal septal abscess in the immunocompromised patient. Otolaryngol Head Neck Surg 2007; 136(3):506-7.

3) Debnam JM, Gillenwater AM, Ginsberg LE. Nasal septal abscess in patients with immunosuppression. AJNR Am J Neuroradiol 2007; 28(10):1878-9.

4) Patel R, Orlandi RR. Fungal septal abscess complicating maxillary sinus fungus balls in an immunocompetent host. Allergy Rhinol (Providence) 2015;6(3):184-7. 
5) Naeem F, Rubnitz JE, Hakim H. Isolated nasal septum necrosis caused by Aspergillus flavus in an immunocompromised child. Pediatr Infect Dis J 2011;30(7):627-9.

6) Cho IK, Chung YJ. A case of nasal septal abscess caused by combined bacterial and fungal infection in the immunocompromised patient. Korean J Otorhinolaryngol-Head Neck Surg 2012;55(6):378-81.

7) Jeong JH, Kim HO, Lee YS, Chung JH. A case of fungal nasal septal abscess in the immunocompromised patient. Korean J OtorhinolaryngolHead Neck Surg 2008;51(11):1061-4.

8) Gradoni P, Fois P. Nasal septal abscess complicating isolated acute sphenoiditis: case report and literature review. B-ENT 2010;6(4): 303-5.
9) Pang KP, Sethi DS. Nasal septal abscess: an unusual complication of acute spheno-ethmoiditis. J Laryngol Otol 2002;116(7):543-5.

10) Gode S, Turhal G, Ozturk K, Aysel A, Midilli R, Karci B. Acute invasive fungal rhinosinusitis: survival analysis and the prognostic indicators. Am J Rhinol Allergy 2015;29(6):e164-9.

11) Ambrus PS, Eavey RD, Baker AS, Wilson WR, Kelly JH. Management of nasal septal abscess. Laryngoscope 1981;91(4):575-82.

12) Walsh TJ, Anaissie EJ, Denning DW, Herbrecht R, Kontoyiannis DP, Marr KA, et al. Treatment of aspergillosis: clinical practice guidelines of the Infectious Diseases Society of America. Clin Infect Dis 2008; 46(3):327-60 